\title{
Fama French Three-factor Model: A Comparative Study
}

Effulgence

Vol. 16 No. 2

July - December, 2018

Rukmini Devi Institute of Advanced Studies

E-mail : effulgence@rdias.ac.in, Website : www.rdias.ac.in

http:/ / effulgence.rdias.ac.in/user/default.aspx

https://dx.doi.org/10.33601/effulgence.rdias/v16/i2/2018/32-41

\section{Smita Datta ${ }^{1} \nabla$ \\ Anindita Chakraborty ${ }^{2}$}

\begin{abstract}
The sector which has the highest weight (31.58\%) in SEP CNX Nifty (the benchmark index of the Indian equity market) is the financial services sector. Therefore, it is very crucial to understand the risk-return trade-off of the stocks belonging to this sector for the purpose of making better investment decision. Hence, this study aims to examine whether the current standard model for asset pricing, the Fama-French three factor model, succeeds in capturing the excess returns of the size and value sorted portfolios of Indian financial services sector stocks. This study aims to fulfil this objective by implementing the Fama-French three factor model to stocks constituting the CNX-finance index and firms comprising the CNX-auto index and comparing the goodness of fit and the pricing error of the model for the financial services sector to those obtained for the auto sector which acts as the benchmark. The empirical findings obtained provide evidence that the Fama-French three factor model can be applied to the Indian financial services sector.
\end{abstract}

Keywords: Fama-French three factor model, risk and return, performance, auto sector, financial services sector.

\section{INTRODUCTION}

$\mathrm{P}$ ricing stocks have always been an area of immense interest for analysts and researchers because equity pricing has varied applications ranging from estimating the cost of capital for firm, judging the performance of portfolios managers and cost-benefit analysis. The most widely used model for this purpose is the Capital Asset Pricing Model (CAPM) put forward by Sharpe (1964) and Lintner
(1965). However, various empirical studies on portfolio returns (Basu, 1977; Bhandari, 1988; Banz, 1981; Stattman, 1980; and Chan et al., 1991) have documented several anomalies. According to one school of thought such anomalies are caused due to the fact that the single factor asset pricing model is mis-specified and the expected return is related to multiple dimensions of risk.

The most popular multifactor asset pricing model is

1. Research scholar, Institute of Management Studies, Banaras Hindu University, Varanasi, smitag@rocketmail.com

2. Assistant professor, Institute of Management Studies, Banaras Hindu University, Varanasi, anindita_19dec@rediffmail.com 
the Fama- French three factor model. Fama and French developed this model through empirical testing of a sample of US non financial firms. However, a serious limitation with empirical models such as this one, which use proxies for non-market sources of risk, is that none of these factors can be clearly identified as hedging a significant source of uncertainty. Black (1993) has cautioned that when the database is scanned repeatedly in search of explanatory factors (which is often referred to as data-snooping) some past "patterns" may be identified that are purely due to chance. But, Fama and French (1995) have succeeded in gathering partial evidence in favour of rational pricing theory behind size and value premium. In order to examine the validity of these two contradicting claims, researchers are focusing extensively on carrying out empirical testing of the three factor model in different countries and in different time periods (out of sample tests).

Several out of sample tests of the Fama-French three factor model have been carried out with Indian equity as sample. Empirical studies (Connor and Sehgal, 2001; Taneja, 2010; Sehgal \& Balakrishnan, (2013) mostly supports the validity of Fama-French three factor model in Indian equity market and indicates that this model does a better job than CAPM in predicting stock returns in the Indian stock market. Following the original study of Fama and French (1993) these Indian studies had also excluded financial stocks from the sample.

However, it is observed that the weight of the financial services sector is highest $(31.58 \%)$ in $\mathrm{S} \& \mathrm{P}$ CNX Nifty. Hence, this study is aimed at examining whether the Fama-French three factor model can predict the stock returns for Indian financial services sector. To attain this objective the performance of the three factor model for the financial sector stocks is compared to its performance for automobile firms. The performance of the three factor model for the automobile sector has been used as a benchmark for judging the performance of the model for the financial services sector because the Fama-French three factor model has been developed on the basis of an empirical study of a sample of manufacturing firms and the auto sector belongs to this category.

The rest of the paper is organised as follows: the second section has been devoted to literature review where prior research in this area have been analysed. In the third section the research methodology that has been employed for carrying out this study has been discussed. The fourth section contains the empirical findings and statistical analysis. Section 5 incorporates the concluding remarks.

\section{LITERATURE REVIEW}

Fama and French (1992) examined the simultaneous effects of firm specific characteristics such as size, past returns, leverage, dividend yields, E/P ratio, $\mathrm{BE} / \mathrm{ME}$ ratio on the cross section of average stock returns of all non-financial firms either in NYSE, AMEX or NASDAQ for the period 1963-1990. The study revealed that market beta fails to explain the mean return on the sample stocks, while size and $\mathrm{BE} / \mathrm{ME}$ ratio capture the cross-sectional variation of stock returns which is associated with all the variables under study. Based on their empirical study of non-financial US firms for the 1963-1990 period Fama-French (1993) argued that the single factor CAPM is inadequate for explaining the cross section of expected returns across stocks and proposed a three factor model that takes into consideration two additional risk factors, namely, size and book to market equity along with market beta.

The empirical evidence of the test of the Fama French three factor model on 364 Indian companies that constitute CRISIL 500 list conducted by Connor and Sehgal (2001), generally support the Fama French model. However, they acknowledged that their study does not provide answer for several pressing questions - whether the Fama-French factors can absorb the excess returns of wider range of portfolios, whether there are evidence of any other pervasive factors affecting returns, whether the 
findings are valid when alternative samples or estimation method are employed, what are the underlying economic theory that can account for the size and value premium.

Bahl (2006) carried out a study on a sample of 79 stocks comprising the BSE-100 index to compare the performance of the CAPM and Fama-French three factor model and to investigate whether any particular month had any specific effect on portfolio returns. The conclusion of the study was that the three factor model does a better job of capturing the cross-sectional variation of portfolio returns compared to the CAPM and seasonal effects on portfolio returns do not exist.

Tripathi (2008) aimed to examine the relationship between four firm characteristics (size, P/E ratio, leverage and book to market equity) and stock returns in India and to test whether alternative asset pricing models formed by incorporating one or more of these four company fundamentals can give an improved explanation of cross-sectional variation in mean returns on India equity using monthly returns of a sample of 455 firms forming part of S \& P CNX 500 index for the period between June 1997 and June 2007. The findings revealed that out of all the possible alternative asset pricing models which can be formulated using different combinations of the four firm specific characteristics the Fama-French model performs best in Indian context.

Taneja (2010) also examined the comparative performance of the CAPM and the Fama-French three factor model by taking a sample of 187 companies belonging to S \& P 500 index for a study period of five years (June 2004- June 2009). On the basis of the study it was concluded that Fama-French model is a better predictor of Indian equity returns than CAPM but the improved explanatory power of the three factor model can be credited to either of the two added factors (size and value).

Sehgal \& Balakrishnan (2013) evaluated the robustness of the standard version of the Fama-
French three factor model with respect to alternative versions of the model using other measures of value (P/E and past sales growth) and size ( enterprise value and total assets) by applying the alternative models on 465 companies that form part of BSE index. They inferred that all the alternative versions of the Fama-French model are identical in terms of performance and are able to provide better description of portfolio returns than the CAPM. But the three factor model failed to fully capture the abnormal returns that remain unexplained by the CAPM.

Jain (2013) made an effort to analyse the performance of Indian stocks that constitute the BSE SENSEX as well as study the sector wise performance using the Fama-French three factor model. The analysis strongly indicated that besides the Fama-French factors some additional factor is required to explain the variation in performance across industrial sectors.

Recently, Singh and Yadav (2015) have undertaken a study using the stocks constituting the CNX 500 index as sample for a period spanning October 1999 to September 2014. This study confirms the findings of the previous studies that the Fama and French three factor model exhibits superior performance than the CAPM in India.

It is evident from the review of literature that the applicability of the Fama-French three factor model in the Indian stock market has been tested repeatedly with different sample stocks in different time periods and with different proxies for size and value factors and all these studies have confirmed the superiority of this model over the traditional CAPM. Thus, the Fama and French three factor model has emerged as the new standard model for pricing the stocks in the Indian market like in other countries around the world. It is also obvious that there is a lack of literature that establishes the validity of the Fama-French three factor model, the current worldwide standard model in asset pricing in the Indian financial sector. Most of the previous 
studies examining the validity of the Fama-French three factor model in the Indian context have excluded financial firms from the sample following the original study of Fama and French (1993) and only two out of these studies cover financial firms. Out of these two the one undertaken by Jain (2013) uses only three financial firms which is too small a sample size to reach any reliable conclusion. The other one by Singh and Yadav (2015) uses as test assets four sets of five portfolios formed on the basis of univariate sorting on size, book-to-market equity ratio, profitability and investment. Hence, the findings of this study is also questionable because it does not follow the standard practice of using test portfolios that are formed from independent double sorts on size and an anomaly variable. This study attempts to bridge this gap by comparing the performance of the Fama-French three factor model with respect to Indian financial services sector stocks to that of the model with respect to a sector of the Indian stock market (auto sector) for which the applicability of the Fama-French three factor model has already been established.

\section{RESEARCH METHODOLOGY}

\section{Sample:}

The sample data for this study pertains to firms that constitute the CNX-finance index and the CNX auto index as of March 2015. However, four stocksAmtek Auto Ltd., Bosch Ltd., Eicher Motors Ltd. and MRF Ltd., comprising the $\mathrm{CNX}$ auto index have been excluded from the sample because they have nonMarch financial year-ending. The month end stock prices of the sample firms have been sourced from the website: www.finance.yahoo.com for the period spanning June 2009 to June 2014. The time series of monthly share prices have been converted into time series of monthly returns using the formula:

$$
\mathrm{R}_{\mathrm{it}}=\left(\mathrm{P}_{\mathrm{it}}-\mathrm{P}_{\mathrm{it}-1}\right) / \mathrm{P}_{\mathrm{it}-1}
$$

Since the dividend yield in India is very small, only the capital gain component has been utilised to compute stock returns.
The book value of equity and number of shares outstanding at March-end of each year from 2009 to 2013 for the sample firms have been taken from the website: www.moneycontrol.com.

The S\&P Nifty, also called Nifty 50 or simply Nifty has been used as a proxy for market portfolio. It is a free float market capitalisation weighted index of 50 financially sound and most actively traded firms on the National Stock Exchange of India Ltd. The stocks comprising Nifty covers 23 sectors of the Indian economy and represents about $66.85 \%$ of the free float market capitalisation of the stocks listed on NSE as of June 30, 2014. The base value of Nifty has been set as 1000 and its base period is November 3, 1995. The risk free rate has been specified by the implicit yield on 91 days Treasury bill obtained from RBI website.

\section{Constructing the size and value sorted portfolios:}

For each sector we rank the firms according to their market capitalisation in June of year ( $\mathrm{t}$ ). If the market capitalisation of a firm is less than the median value it is classified as Small (S) otherwise it is placed the category Big (B). Similarly the constituent stocks of each sector are ranked according to $\mathrm{BE} / \mathrm{ME}$ ratio measured in March of year ( $t$ ) and then divided into three categories: Low (L) bottom 30\%, Medium (M) $30 \%$ to $70 \%$ and High $(\mathrm{H})$ above $70 \%$. The monthly returns on each stock are computed from July of year $(\mathrm{t})$ to June of year $(\mathrm{t}+1)$. The ranking is revised in the month of June of each subsequent year and the procedure for sorting stocks into various portfolios is repeated. Since for some companies there may be delayed release of financial statements, there may be a lag between the end of the fiscal year and the time when the information is available to the investors for decision making purpose. Therefore, the study form portfolios with three months gap from financial closing. These six portfolios (HB, HS, MB, MS, LB and LS) formed from independent double $2 \times 3$ sorts on size and $\mathrm{BE} / \mathrm{ME}$ ratio have been employed as test portfolios. 


\section{Constructing the Factor Portfolios:}

The Fama French three factor model comprises of three explanatory factors: the market factor (MKT), the size factor (SMB) and the value factor (HML). The monthly return on Nifty fifty minus the risk-free rate is the value of the variable MKT for that month. The difference between mean monthly returns of three small stock portfolios (SL, SM and SH) and that of the three big stock portfolios (BL, BM and $\mathrm{BH}$ ) of a sector is the value of the variable SMB for that sector for that given month. The monthly value of the variable HML for a sector is computed as the difference between mean monthly returns of the two high value portfolios ( $\mathrm{SH}$ and $\mathrm{BH}$ ) and the arithmetic mean of the monthly returns of two low BE/ME portfolios (SL and BL) for that sector.

\section{Model Specification and Regression:}

Time series multiple regression technique is applied to regress the excess returns on the size-value sorted portfolios on returns on market, SMB and HML using the Fama-French three factor model which is expressed in the form of:

$R_{i t}-R_{f t}=a_{i}+b_{i}\left(R_{m t}-R_{f t}\right)+{ }_{s t}(S M B)_{t}+h_{t}(H M L)_{t}+e_{i t}$

\section{EMPIRICAL RESULTS}

\section{Descriptive Statistics}

Table 1 : Summary Statistics on the Portfolio Returns for the financial services sector

\begin{tabular}{|c|c|c|c|c|}
\hline Portfolio & Mean & Standard Deviation & Skewness & Kurtosis \\
\hline HB & -.062574 & .1116633 & .299 & .797 \\
\hline HS & -.043453 & .1189922 & .749 & 2.081 \\
\hline MB & -.057165 & .0976842 & .208 & .094 \\
\hline MS & -.057743 & .0985017 & -.005 & .068 \\
\hline LB & -.068785 & .0970040 & -1.974 & 7.254 \\
\hline LS & -.061560 & .0773551 & -.139 & 2.125 \\
\hline Market_factor & -.06 & .058 & .173 & -.421 \\
\hline SMB & .008589 & .0500586 & .198 & .712 \\
\hline HML & .012159 & .0880202 & .821 & 1.261 \\
\hline
\end{tabular}

Where,

$\mathrm{R}_{\mathrm{it}}=$ Rate of return on i-th asset in time ' $\mathrm{t}^{\prime}$

$R_{m t}=$ Rate of return on market portfolio in time' $t^{\prime}$

$R_{\mathrm{ft}}=$ Rate of return on risk free assets in time' $\mathrm{t}^{\prime}$

$\mathrm{SMB}_{\mathrm{t}}=$ Small minus Big i.e. returns of a portfolio of small stocks in excess of the returns of a portfolio of large stocks in time' $\mathrm{t}^{\prime}$

$\mathrm{HML}_{\mathrm{t}}=$ High minus Low ie. returns of a portfolio of stocks with high book to market ratio in excess of the return on a portfolio of stocks with low book to market ratio in time ' $t$ '

$\mathrm{a}_{\mathrm{i}}=$ unconditional mean return of $\mathrm{i}$-th asset

$b_{i}=$ the coefficient loading of the $i$-th asset for excess return of the market portfolio over the risk free rate $\mathrm{S}_{\mathrm{i}}=$ the coefficient loading of the i-th asset for the excess average return of portfolios with small equity class over portfolios of big equity class

$\mathrm{h}_{\mathrm{i}}=$ the coefficient loading of the i-th asset for the excess average return of portfolios with high book-to market equity class over those with low book-tomarket equity class

$\mathrm{e}_{\mathrm{it}}=$ error term for asset $\mathrm{i}$ at time $\mathrm{t}$

The Ordinary Least Square method is used for regression analysis. 
Table 2 : Summary Statistics on the Portfolio Returns for the auto sector

\begin{tabular}{|c|c|c|c|c|}
\hline Portfolio & Mean & Standard Deviation & Skewness & Kurtosis \\
\hline HB & -.032943 & .1320272 & .794 & 1.066 \\
\hline HS & -.039158 & .1203490 & .570 & .976 \\
\hline MB & -.060132 & .1095115 & -1.291 & 6.761 \\
\hline MS & -.056829 & .1040207 & .133 & 3.058 \\
\hline LB & -.051426 & .0734992 & .177 & .434 \\
\hline LS & -.031019 & .0909458 & -.221 & -.612 \\
\hline Market_factor & -.062420 & .0583090 & .173 & -.421 \\
\hline SMB & .005832 & .0603172 & .050 & -.144 \\
\hline HML & .005172 & .0813273 & .681 & 1.075 \\
\hline
\end{tabular}

Table 1 and Table 2 summarize the descriptive statistics for response variable (six portfolios) and the explanatory variables (factor portfolios) used in the multiple time series regressions for the financial services sector and auto sector respectively. In case of the financial services sector, for the three small sized portfolios the average return ranged between $4.35 \%$ to $-6.16 \%$ while for the three big portfolios the same ranged between $-5.72 \%$ to $-6.88 \%$. For the auto sector stocks, while the mean returns earned by the portfolios of small firms varied between $-3.1 \%$ to $5.68 \%$ the same ranged between $-3.29 \%$ to $-6.01 \%$ for the portfolios of big firms. Hence, for both the sectors the inverse relationship between size and average monthly return of portfolios as claimed by Banz (1981) and Fama-French (1992) has been validated. With respect to the value premium, it was found that for financial services sector, the average portfolio return declined from high to medium $\mathrm{BE} / \mathrm{ME}$ ratio and further declined from medium to low book to market ratio. This finding is in agreement with the evidence obtained by Fama and French (1992) for US stocks as well those obtained by Connor and Sehgal (2001) for Indian stocks who found that a strong positive relationship exists between book-to-market equity ratio and stock returns. But for the auto sector this relationship was not validated because mean return of the medium $\mathrm{BE} / \mathrm{ME}$ ratio portfolios were lower than those of the high $\mathrm{BE} / \mathrm{ME}$ portfolios, but the returns of portfolios containing low $\mathrm{BE} / \mathrm{ME}$ stocks were higher than the ones containing the stocks with medium $\mathrm{BE} / \mathrm{ME}$ ratio.

\section{Correlation between the Factor Portfolios}

Fama-French model is free from the From Table 3 and Table 4 it was observed that for none of the two sectors there is any strong significant correlation between any pair of factor portfolios. This implied that with respect to both the sectors the problem of multi-collinearity.

Table 3 : Correlation between the Factor Portfolios of Financial Services Sector

\begin{tabular}{|l|r|r|r|}
\hline & Market_factor & SMB & HML \\
\hline Market_factor & 1 & $-.314^{*}$ & $.381^{* *}$ \\
Pearson Correlation & & .015 & .003 \\
Sig. (2-tailed) & 60 & 60 & 60 \\
N & $-.314^{*}$ & 1 & .063 \\
\hline SMB & .015 & 60 & .633 \\
Pearson Correlation & 60 & 063 & 60 \\
Sig. (2-tailed) & $.381^{* *}$ & .603 & 1 \\
N & 60 & 60 & 60 \\
HML & 60 . & & \\
Pearson Correlation & & & \\
Sig. (2-tailed) & & & \\
N & & & \\
\hline
\end{tabular}

${ }^{*}$ Correlation is significant at the 0.05 level (2-tailed).

${ }^{* *}$ Correlation is significant at the 0.01 level (2-tailed). 
Table 4 : Correlation between the Factor Portfolios of Auto Sector

\begin{tabular}{|c|c|c|c|}
\hline & Market_factor & SMB & HML \\
\hline $\begin{array}{l}\text { Market_factor } \\
\text { Pearson Correlation } \\
\text { Sig. (2-tailed) } \\
\text { N }\end{array}$ & $\begin{array}{r}1 \\
60\end{array}$ & $\begin{array}{r}-.049 \\
.708 \\
60\end{array}$ & $\begin{array}{r}.392^{* *} \\
.002 \\
60\end{array}$ \\
\hline $\begin{array}{l}\text { SMB } \\
\text { Pearson Correlation } \\
\text { Sig. (2-tailed) } \\
\text { N }\end{array}$ & $\begin{array}{r}-.049 \\
.708 \\
60\end{array}$ & $\begin{array}{r}1 \\
60\end{array}$ & $\begin{array}{r}.187 \\
.153 \\
60\end{array}$ \\
\hline $\begin{array}{l}\text { HML } \\
\text { Pearson Correlation } \\
\text { Sig. (2-tailed) } \\
\text { N }\end{array}$ & $\begin{array}{r}.392^{\text {** }} \\
.002 \\
60\end{array}$ & $\begin{array}{r}187 \\
.153 \\
60\end{array}$ & 60 \\
\hline
\end{tabular}

${ }^{* *}$ Correlation is significant at the 0.01 level (2-tailed)

\section{Time-series regression}

Table 5 : Results of Time-series regression for the financial services sector

\begin{tabular}{|c|c|c|c|c|c|}
\hline S. No. & Portfolio & Intercept & Independent variable & $\begin{array}{l}\text { Adjusted } \\
\mathbf{R}^{2}\end{array}$ & F-statistic \\
\hline 1 & $\mathrm{HB}$ & $\begin{array}{l}-.002 \\
(.871)\end{array}$ & $\begin{array}{lc}\text { Market factor }(8.600, .000) \\
\text { SMB } & (-2.406, .019) \\
\text { HML } & (8.233, .000)\end{array}$ & .820 & $\begin{array}{r}90.679 \\
(.000)\end{array}$ \\
\hline 2 & HS & $\begin{array}{l}.009 \\
(.490)\end{array}$ & $\begin{array}{lc}\text { Market factor } & (6.451, .000) \\
\text { SMB } & (3.377, .001) \\
\text { HML } & (6.673, .000)\end{array}$ & .717 & $\begin{array}{c}50.753 \\
(.000)\end{array}$ \\
\hline 3 & MB & $\begin{array}{l}.017 \\
(.107)\end{array}$ & $\begin{array}{lc}\text { Market factor }(9.327, .000) \\
\text { SMB } & (-.424, .673) \\
\text { HML } & (3.043, .004)\end{array}$ & .726 & $\begin{array}{l}53.236 \\
(.000)\end{array}$ \\
\hline 4 & MS & $\begin{array}{l}.015 \\
.(288)\end{array}$ & $\begin{array}{lc}\text { Market factor }(7.008, .000) \\
\text { SMB } & (1.942, .057) \\
\text { HML } & (.872, .387)\end{array}$ & .521 & $\begin{array}{l}22.394 \\
(.000)\end{array}$ \\
\hline 5 & LB & $\begin{array}{l}.008 \\
(.517)\end{array}$ & $\begin{array}{lc}\text { Market factor }(6.875, .000) \\
\text { SMB } & (-4.111, .000) \\
\text { HML } & (-3.979, .000)\end{array}$ & .623 & $\begin{array}{c}33.559 \\
(.000)\end{array}$ \\
\hline 6 & LS & $\begin{array}{l}.000 \\
(.960)\end{array}$ & $\begin{array}{lc}\text { Market factor } & (8.038, .000) \\
\text { SMB } & (6.813, .000) \\
\text { HML } & (-3.433, .001)\end{array}$ & .572 & $\begin{array}{l}27.317 \\
(.000)\end{array}$ \\
\hline
\end{tabular}

Table 6 : Results of Time-series regression for the auto sector

\begin{tabular}{|c|c|c|c|c|c|}
\hline S. No. & Portfolio & Intercept & Independent variable & $\begin{array}{l}\text { Adjusted } \\
\mathbf{R}^{2}\end{array}$ & F-statistic \\
\hline 1 & HB & $\begin{array}{l}.051 \\
(.000)\end{array}$ & $\begin{array}{lc}\text { Market factor } & (9.453, .000) \\
\text { SMB } & (-3.375, .001) \\
\text { HML } & (7.020, .000)\end{array}$ & .799 & $\begin{array}{l}79.309 \\
(.000)\end{array}$ \\
\hline 2 & HS & $\begin{array}{l}.010 \\
(.363)\end{array}$ & $\begin{array}{lc}\text { Market factor }(6.672, .000) \\
\text { SMB } & (5.941, .000) \\
\text { HML } & (7.052, .000)\end{array}$ & .779 & $\begin{array}{l}70.450 \\
(.000)\end{array}$ \\
\hline 3 & MB & $\begin{array}{l}.003 \\
(.843)\end{array}$ & $\begin{array}{lc}\text { Market factor }(4.735, .000) \\
\text { SMB } & (-3.558, .001) \\
\text { HML } & (.891, .377) \\
\end{array}$ & .421 & $\begin{array}{l}15.297 \\
(.000)\end{array}$ \\
\hline 4 & MS & $\begin{array}{l}.010 \\
(.473)\end{array}$ & $\begin{array}{lc}\text { Market factor }(6.757, .000) \\
\text { SMB } & (2.954, .005) \\
\text { HML } & (1.868, .067)\end{array}$ & .569 & $\begin{array}{l}26.918 \\
(.000)\end{array}$ \\
\hline 5 & LB & $\begin{array}{l}.014 \\
(.159)\end{array}$ & $\begin{array}{lc}\text { Market factor }(8.596, .000) \\
\text { SMB } & (-1.913, .061) \\
\text { HML } & (-2.818, .007)\end{array}$ & .577 & $\begin{array}{l}27.859 \\
(.000)\end{array}$ \\
\hline 6 & LS & $\begin{array}{l}.048 \\
(.000)\end{array}$ & $\begin{array}{lc}\text { Market factor } & (9.253, .000) \\
\text { SMB } & (4.007, .000) \\
\text { HML } & (-3.019, .004) \\
\end{array}$ & .610 & $\begin{array}{l}31.748 \\
(.000)\end{array}$ \\
\hline
\end{tabular}


The results of the time series regressions for financial services sector, (Table 5) revealed that for each of the six test portfolios the Fama-French model fitted well because each of the six F-statistics were significant. The existence of size effect was confirmed in the financial services sector because the ' $s$ ' coefficient were positive for portfolios consisting of small stocks and became negative for portfolios of large stocks. The ' $h$ ' coefficient was negative for portfolios containing stocks with low book to market ratio and became positive for portfolios containing stocks with high $\mathrm{BE} / \mathrm{ME}$ ratio which confirmed the existence of value premium for financial services sector stocks. Further, the model succeeded in explaining a considerable portion $(66.3 \%)$ of the variability in portfolio returns. Moreover, all the factor loadings were significant except for the coefficient for the SMB factor for both the medium BE/ME portfolios and the HML factor for the MS portfolio. On the basis of this finding it was evident that market factor has the highest explanatory power but the other two factors could not be conclusively ranked in terms of their ability to explain the cross-section of returns within Indian financial services sector.
Similarly, for the auto sector, from multiple regression analysis it was seen (Table 6) that for each of the six test assets the F-statistic was significant indicating goodness of model fit. The signs of the's' coefficients and ' $h$ ' coefficients were in conformity with size and value effect respectively. On the basis of average adjusted R2 it was established that the three Fama-Frech risk factors (market factor, SMB and HML) can explain $62.6 \%$ of the variability of portfolio returns for auto stocks. Also, it was found that the market factor has all significant exposures while the coefficients of HML and SMB were significant for four and five portfolios respectively. This finding signified that like in case of financial service sector stocks, the market factor has the highest explanatory power for auto stocks as well, but the ranking of the explanatory power of the other two factors was ambiguous.

\section{Measure of Goodness of Fit and Measure of Abnormal Return}

On the basis of adjusted R2 criterion (measure of goodness of fit), it can be stated that the FamaFrench three factor model holds for Indian financial

Table 7 : Comparative performance of the Fama-french three factor model for financial services sector and auto sector

\begin{tabular}{|c|c|c|}
\hline Sector & Mean Absolute Alpha & Mean R $^{\mathbf{2}}$ \\
\hline Financial services & 0.0085 & 0.663 \\
\hline Auto & 0.0227 & 0.626 \\
\hline
\end{tabular}

service sector stocks because the average adjusted R2 for this sector was found to be in the same range as that of the benchmark auto sector.

If an asset pricing model is accurate, then the intercept terms of the time series regression should be equal to or close to zero, which implies that the risk factors constituting the pricing model are able to completely account for the cross-sectional variation of stock returns. Hence, to complete analysis, study had also examined the zero intercepts hypothesis. The method of using mean absolute alpha has been employed to test this hypothesis. The mean absolute alpha (measure of abnormal return) of the financial services sector has been compared to that of the auto sector and it was found that the model appears to perform better for the financial service sector stocks than the benchmark auto sector because the latter has substantially high mean absolute alpha (.0227) in comparison to the former (.0085).

To summarize, the results obtained clearly indicate that the Fama-French three factor model can be applied to the Indian financial services sector. 


\section{CONCLUSION}

This study evaluates the efficacy of the Fama- French three factor model in explaining the returns on size and value sorted portfolios of financial service sector firms. The efficacy has been measured by comparing the goodness of fit and absolute pricing error of the model for the financial services sector to those of the model for auto stocks.

The findings have established the applicability of Fama and French three factor model on the Indian financial service sector firms. Furthermore, comparison with the benchmark sector (i.e. the auto sector) shows that this model can better explain the cross-section of average stock returns for this sector than the auto stocks as indicated by the value of mean absolute alpha for the respective sectors. Of the three explanatory variables market factor plays a more vital role than the other two as indicated by the number of significant exposures of each of the three risk factors.

The value of R2 for both the sectors and significant intercept terms for two portfolios out of the six auto stock portfolios indicate that there has to be some other risk factor besides these three that affect stock returns for these sectors. These additional factors may be momentum (Carhart, 1997) and/or industry concentration (Hou and Robinson, 2006). Future research should aim at examining whether asset pricing models incorporating these factors can better explain the cross-sectional variation of average stock returns for these sectors and for the Indian equity market as a whole.

\section{REFERENCES}

1) Banz, R. W. (1981), "The Relationship between Return and Market Value of Common Stocks", Journal of Financial Economics, 9(1): 3-18.

2) Bahl, B. (2006), "Testing the Fama and French Three-factor Model and its Variants for the Indian Stock Returns", Retrieved May 22, 2015, from http:/ / dx.doi.org/10.2139/ssrn.950899.
3) Basu, S. (1977), “Investment Performance of Common Stocks in relation to their Price-earnings Ratios: A Test of the Efficient Market Hypothesis", The Journal of Finance, 32(3): 663-682.

4) Bhandari, L. C. (1988), “Debt/equity Ratio and Expected Common Stock Returns: Empirical Evidence", The Journal of Finance, 43(2): 507-528.

5) Black, F. (1993), "Beta and Return", The Journal of Portfolio Management, 20(1): 8-18.

6) Carhart, M. M. (1997), “On Persistence in Mutual Fund Performance", The Journal of Finance, 52(1): 57-82.

7) Chan, L. K., Hamao, Y. and Lakonishok, J. (1991), "Fundamentals and Stock Returns in Japan", The Journal of Finance, 46(5): 1739-1764.

8) Connor, G. and Sehgal, S. (2001), "Tests of the Fama and French Model in India", Discussion Paper, [379], Financial Markets Group, ANESRC Research Centre, London School of Economics, London, May.

9) Fama, E. F. and French, K. R. (1992), "The Crosssection of Expected Stock Returns", The Journal of Finance, 47(2): 427-465.

10) Fama, E. F. and French, K. R. (1993), “Common Risk Factors in the Returns on Stocks and Bonds", Journal of Financial Economics, 33(1): 356.

11) Fama, E. F., and French, K. R. (1995), “Size and Book-to-market Factors in Earnings and Returns. The Journal of Finance, 50(1): 131-155.

12) Hou, K. and Robinson, D. T. (2006), "Industry Concentration and Average Stock Returns", The Journal of Finance, 61(4): 1927-1956.

13) Jain, S. (2013), "Fama-French Three Factor Model in Indian Stock Market", The Current Global Trends, 2(1): 7-13.

14) Lintner, J. (1965), “The Valuation of Risk Assets and the Selection of Risky Investments in Stock Portfolios and Capital Budgets", The Review of Economics and Statistics, 47: 13-37.

15) Sehgal, S. and Balakrishnan, A. (2013), "Robustness of Fama-French Three Factor Model: Further Evidence for Indian Stock 
Market", Vision: The Journal of Business Perspective, 17(2): 19-127.

16) Sharpe, W. F. (1964), "Capital Asset Prices: A Theory of Market Equilibrium under Conditions of Risk", The Journal of Finance, 19(3): 425-442.

17) Singh, S., and Yadav, S. S. (2015). Indian stock market and the asset pricing models. Procedia Economics and Finance, 30, 294-304.

18) Stattman, D. 1980, "Book Values and Stock Returns", The Chicago MBA: A Journal of Selected Papers, 4(1): 25-45.

19) Taneja, Y. P. (2010), "Revisiting Fama French Three-factor Model in Indian Stock Market", Vision: The Journal of Business Perspective, 14(4): 267-274.

20) Tripathi, V. (2008), “Company fundamentals and equity returns in India", paper presented at the 21st Australasian Finance and Banking Conference, Sydney, Australia. 